\title{
Ciudades turísticas latinoamericanas, relatos posibles desde las artes visuales. El caso de Punta del Este
}

\author{
LATIN AMERICAN TOURIST CITIES, POSSIBLE STORIES FROM THE VISUAL ARTS: \\ THE CASE OF PUNTA DEL ESTE
}

\section{CIDADES TURÍSTICAS DA AMÉRICA LATINA, POSSÍVEIS HISTÓRIAS DAS ARTES VISUAIS. O CASO DE PUNTA DEL ESTE}

\author{
Federico Sequeira $* 1$ \\ fsequeira@cure.edu.uy
}

\begin{abstract}
Resumen
Punta del Este es una de las ciudades turísticas más reconocidas en América del Sur, sus características de enclave turístico global y su condición de pueblo de pescadores devenido en balneario internacional, la colocan como posible ejemplo para entender cómo las vertiginosas transformaciones de las ciudades turísticas no sólo afectan el ambiente y el paisaje, sino también las relaciones sociales y las de los sujetos con su entorno. Este permanente estado de transformación, que muchas veces coloca a la excepcionalidad como regla, genera una compleja trama de desigualdad, de inclusiones y exclusiones, de recibimientos y expulsiones. Si bien existen antecedentes académicos de investigaciones que han indagado en estos temas, resulta de interés hacerlo desde las artes visuales. En su calidad de "dispositivos del recuerdo" (Giunta, 2014) aportan a la memoria social y política de las ciudades, construyendo otros relatos posibles sobre el vínculo entre los individuos y su entorno, su ambiente. Posiblemente una reflexión sobre estos temas desde el campo de las artes visuales contribuirá a dar cuenta de las complejas relaciones que en las ciudades turísticas se establecen entre quienes las habitan y quienes las visitan, cómo lo hacen, cómo las relatan y cómo las representan.
\end{abstract}

Palabras claves: globalización, turismo, ambiente, identidad, artes visuales

\author{
Abstract \\ Punta del Este is one of the most recognized tourist cities in South America, and its \\ characteristics as a global tourist enclave and its status as a fishing village turned

\footnotetext{
1 *Centro Universitario Región Este de la Universidad de la República
} 
into an international seaside city, make it into a useful case study to understand how the vertiginous transformations of tourist cities affect the environment, the landscape and also social relations, between people and also between people and the environment. This permanent state of transformation, which often makes exceptionality the rule, generates complex situations of inequality, of inclusions and exclusions, of receptions and expulsions. Although there is an academic background of research that has investigated these issues, it is interesting to do so from the perspective of the visual arts. As "memory devices" (Giunta, 2014) they contribute to the social and political memory of cities, favoring other possible stories about the link between individuals and their environment. A reflection on these issues through a visual arts frame potentially helps to account for the complex relationships that are established in tourist cities between those who inhabit them and those who visit them, how they do so, how they relate to them and how they represent them.

Keywords: globalization, tourism, environment, identity, visual arts

\section{Resumo}

Punta del Este é uma das cidades turísticas mais reconhecidas da América do Sul, suas características como enclave turístico global e sua condição de vila de pescadores transformada em um balneário internacional, colocam-na como um exemplo possível para entender como as transformações vertiginosas das cidades turísticas afetam não apenas o meio ambiente e a paisagem, mas também as relações sociais $e$ as dos sujeitos com o meio ambiente. Esse estado permanente de transformação, que muitas vezes coloca a excepcionalidade como regra, gera uma complexa teia de desigualdades, de inclusões e exclusões, de recebimentos e expulsões. Embora exista uma formação acadêmica de pesquisa que investigue essas questões, é interessante fazê-lo a partir das artes visuais. Como "dispositivos de memória" (Giunta, 2014), contribuem para a memória social e política das cidades, construindo outras histórias possíveis sobre a ligação entre os indivíduos e seu meio, seu meio ambiente. Possivelmente uma reflexão sobre essas questões a partir do campo das artes visuais contribuirá para dar conta das complexas relações que se estabelecem nas cidades turísticas entre quem as habita e quem as visita, como o fazem, como se relacionam e como representam.

Palavras-chave: globalização, turismo, meio ambiente, identidade, artes visuais 


\section{A modo de introducción}

La lógica dominante de las ciudades turísticas latinoamericanas, como el caso de Punta del Este, produce tensiones. Por ejemplo, las producidas entre el desarrollo y el cuidado del ambiente; las que suceden entre los habitantes locales y los migrantes pobres que llegan al territorio procurando una mejor calidad de vida; o la pérdida de referencias de memoria debido al avasallamiento del patrimonio arquitectónico y a las constantes modificaciones del paisaje urbano. Estos conflictos, producidos fundamentalmente por las disputas de los territorios, resultan invisibilizados por un relato dominante, acordado entre los agentes del sector turístico, cuyo objetivo es preservar una dinámica que pudiendo resultar redituable en el corto plazo, representa incertidumbre hacia el futuro. Considerando esto, el presente trabajo se propone indagar en algunas expresiones de las artes visuales locales, en tanto dispositivos generadores de discurso a través de imágenes, para identificar enunciaciones críticas que aporten a la reflexión colectiva.

\section{Punta del Este, un enclave turístico global en América Latina}

Si bien Punta del Este, a diferencia de New York, Londres o Tokio, no forma parte de la "red transnacional de las ciudades globales" (Sassen, 1995) porque no se trataría cabalmente de una, se encuentra plenamente inmersa en las lógicas dominantes del capital y se suceden en este territorio un conjunto de relaciones que la vinculan al concepto de ciudad global.

Para el caso de Miami, George Yúdice (2002) la señala como una "ciudad mundial menor" (p. 236). Si bien Punta del Este en ocasiones ha sido considerada como la "Miami del sur", ${ }^{2}$ no estaría-ni por su ubicación geográfica, ni por el grado de desarrollo de su infraestructura y servicios-en condiciones de disputarle a la ciudad-puerto estadounidense su condición de "capital cultural latinoamericana" (Yiúdice, 2002, p. 239). Sin embargo, podrían establecerse algunas similitudes entre ambas ciudades, por ejemplo, la migración latinoamericana, preponderantemente interna pero incipientemente del resto de América Latina en el caso del balneario uruguayo. La presencia de las élites financieras globales, si bien Punta del Este no es sede de grandes corporaciones, hay circulación de destacados miembros de esas élites, cuyas altas exigencias en infraestructura y servicios resultan notorias. El desarrollo de la construcción en alianza con los

\footnotetext{
2 En las palabras de Ajmat "[L]a gran cantidad de emprendimientos inmobiliarios que está dibujando en La Mansa un perfil semejante a lo más sofisticado de Miami, con una sucesión de colosales torres con vista al mar, edificios de vidrio que reflejan el atardecer en sus balcones y opacaron hasta al mítico Conrad, reducido a una silueta kitsch más entre todas las construcciones de la costa..." (2018).
} 
sectores inmobiliario y hotelero, o la presencia de emprendimientos de la misma firma en ambas ciudades. ${ }^{3}$

Las características que asocian a Punta del Este a esta idea de territorio global-probablemente aplicable a otros enclaves turísticos latinoamericanos-incluye también las tensiones entre sus habitantes, pero también entre ellos y el propio lugar y cómo se refleja en los vertiginosos cambios del paisaje urbano.

Entre estas características, algunas mencionadas anteriormente, pueden señalarse: la instalación de emprendimientos inmobiliarios y hoteleros, asociados a capitales internacionales ${ }^{4}$ y cuyo público objetivo son las élites; la organización de determinados eventos artístico-culturales con apertura al mundo ; los incentivos para la radicación de empresas asociadas al desarrollo de capacidades locales $^{6}$; la presencia e incipiente radicación de destacados personajes del jet set criollo-fundamentalmente rioplatense-potenciado por la actual coyuntura pandémica; y el desarrollo, a través de inversión pública, de infraestructura ${ }^{7}$ estratégica.

Como contracara de estas características, en clave de tensiones, se podrían mencionar:

La ubicación geográfica de Punta del Este que a diferencia de Miami, no cuenta con "la ubicación más conveniente en todo el hemisferio para los que viajan tri-continentalmente en América Latina, Europa y Estados Unidos" (Yúdice, 2002, p. 243); además de las condiciones climáticas locales que generan una concentración de las actividades durante los meses de verano, siendo permanentes-al menos en los discursos-las búsquedas de estrategias de "desestacionalización".

El fortalecimiento de una alianza productiva acotada, centrada en la construcción y el turismo, impulsado por los llamados "boom(s) de la construcción", cuyos efectos a corto plazo han sido la generación de puestos de trabajo pero a mediano y largo plazo, no solo han afectado el paisaje-por ejemplo la skyline local, con edificios cada vez más altos-sino también la sustentabilidad ambiental, con emprendimientos no adaptados a su entorno. Así como la búsqueda

\footnotetext{
${ }^{3}$ Por ejemplo: los restaurantes "Parador La Huella" en José Ignacio y “Quinto La Huella” en Miami; los emprendimientos inmobiliarios Yoo Punta del Este y Yoo Metropica (Miami); o las Trump Tower(s), aún en construcción la de Punta del Este.

4 Por ejemplo, la ya mencionada Trump Tower (aún en construcción), Fendi Château (aún en construcción), Cipriani Ocean Resort and Club (por construirse) o Estancia Vik en José Ignacio.

${ }^{5}$ Por ejemplo, la feria internacional de galerías de arte "Este Arte" que se realiza en el Centro de Convenciones y Exhibiciones de Punta del Este.

${ }^{6}$ Por ejemplo, la Zona Franca Audiovisual que se instalará en la zona y su potencial vínculo con instituciones orientadas a la formación como la Licenciatura en Medios Audiovisuales (CURE-UdelaR)

${ }^{7}$ Por ejemplo, el Aeropuerto de Laguna del Sauce, la ruta perimetral, el Centro de Convenciones y Exhibiciones de Punta del Este, el Puente de Laguna Garzón, etc.
} 
de "desestacionalización" de las actividades turísticas, han existido intentos de ampliar esa alianza productiva acotada. En ese sentido, se ha incentivado, como ya fue mencionado, la radicación de empresas asociadas al desarrollo de capacidades locales, entre ellas las propuestas enmarcadas en régimen de zonas francas. El principal riesgo de esta lógica, es que estos proyectos se nutran del know how local-producido fundamentalmente por la inversión educativa del país-y no generen más que algunos puestos de trabajo como beneficio para la zona.

Tensiones para la convivencia como consecuencia de la irrupción de estos emprendimientos-inmobiliarios y hoteleros-con sus servicios asociados (principalmente restaurantes y centros comerciales) que representan una suerte de conquista de los territorios costeros. Esta lógica expulsa a las poblaciones locales de su costa natal, generando un corrimiento que produce una expansión de la ciudad hacia las zonas más alejadas de la costa, acompañado esto por el crecimiento de una periferia pobre, engrosada por poblaciones no locales que llegan a este territorio procurando un mejor porvenir. En ese sentido, la ciudad deviene en escenario de disputa, produciéndose tensiones entre los locales-desplazados por los intereses del capital, del que obtienen beneficios económicos-y los migrantes, nacionales e incipientemente de otras latitudes latinoamericanas, que son señalados por los primeros como los causantes de todos los males. Toda esta fragmentación, sumado a las carencias materiales que estas dinámicas producen, representan un gran desafío para las políticas públicas en general y particularmente para las del sector turístico, cuya sustentabilidad parecería estar en tela de juicio.

El aumento de los precios de las viviendas, tanto en alquileres como en compraventas, es una de las consecuencias más notorias de la disputa por los territorios. Este efecto de la especulación inmobiliaria constituye un problema social en un territorio cuyo aumento poblacional es constante.

El espacio urbano como "no ciudad", es decir, como espacios sin memoria, sin pertenencia y sin identidad. Esta consecuencia, del modelo de desarrollo turístico predominante, no es generalmente, objeto de crítica por los locales sino que tienden a justificarlo por los beneficios económicos que genera. Sin embargo, esa pérdida de "identidad cultural" que a menudo sienten, es frecuentemente atribuida a los migrantes, no visualizando el potencial, en términos de diversidad cultural, que representa su llegada. La reciente demolición del ex Hotel San Rafael ${ }^{8}$ es un ejemplo, y no es el único, ${ }^{9}$ de pérdida de esos "mojones de memoria" tan

\footnotetext{
${ }^{8}$ Como señala Martinez (2019): El enorme edificio, inaugurado en 1948, fue durante décadas uno de los hoteles más prestigiosos del Sudamérica: estrellas del Hollywood visitaron su casino y sus salones de estilo Tudor y el Che Guevara se alojó en una de sus 130 habitaciones cuando el enorme Salón Gótico recibió la Reunión de Presidentes de América en 1967. También fue sede de las cumbres de La Ronda de Uruguay, el GATT y la OEA. El edificio había sido decorado con materiales lujosos, como pizarras de Portugal o carpitería en laurel de Chile, y sobre todo, contaba con unos espectaculares murales del artista Norberto Berdía.

${ }^{9}$ En los últimos años fueron demolidos otros edificios de referencia como el Centro del Espectáculo, una obra del Ingeniero Eladio Dieste; el Hotel Playa y la casa Loma Verde.
} 
necesarios para fortalecer la identidad colectiva y también para "producir ciudad". No solamente desde el punto de vista de la pérdida física de un edificio, sino también de la pérdida del espacio que fue escenario de determinados hechos relevantes para la comunidad. En ese sentido, debido fundamentalmente a la especulación inmobiliaria, se genera un cambio en el paisaje físico (el edificio ya no está) y también en el paisaje subjetivo, la referencia física de un recuerdo tampoco está.

Se impone un debilitamiento del Estado por la propia dinámica económica. Esto implica desde la excepcionalidad en la normativa para la construcción, pasando por algún tipo de renuncia fiscal, hasta la flexibilización en la aplicación de las normas y sus controles o la inversión pública para las grandes obras de infraestructura. Se percibe una característica paradoja de la lógica capitalista que, independientemente de la orientación de los gobiernos, exige Estados débiles-flexibles-en la aplicación de las normas pero fuertes en cuanto a la inversión en infraestructuras y protección de la propiedad privada.

Para legitimar esta dinámica, que no sólo se constituye en perjuicios, sino que ha sido beneficiosa en muchos aspectos, resulta necesaria la construcción de un discurso hegemónico, un relato oficial, que armonice, que amalgame y que en sus efectos invisibilice los cuestionamientos, las contradicciones, las tensiones, los conflictos, es decir, la desigualdad que produce este modelo de "desarrollo".

\section{El relato oficial}

En ese sentido, según la página web oficial del Ministerio de Turismo uruguayo, se trata del "balneario de mayor glamour de América" (sic) "donde el lujo y la naturaleza convergen".10 Se registra, posiblemente desde mediados del siglo XX con la realización de los Festivales Internacionales de Cine organizados por Mauricio Litman junto con la Comisión Nacional de Turismo y que atrajo a las principales figuras del cine mundial, un impulso del balneario como destino global. Ese discurso hegemónico de alguna manera desconoce lo latinoamericano, refiriéndose al destino como "uno de los principales balnearios de América y el más exclusivo de la región" (sic), ${ }^{11}$ capaz de "satisfacer las necesidades de los paladares turísticos más exigentes y heterogéneos” (sic). ${ }^{12}$

\footnotetext{
10 "Lujosas residencias de veraneo, altos edificios de apartamentos frente al mar, enormes yates en el puerto, hoteles y restaurantes de lujo lo transforman en el balneario de mayor glamour de América" [Ministerio de Turismo del Uruguay, 2019].

11 "Punta del Este. Donde el lujo y la naturaleza convergen... reconocido internacionalmente como uno de los principales balnearios de América y el más exclusivo de la región. Se ubica en el departamento de Maldonado, a sólo una hora y media de la capital del país" (Ministerio de Turismo del Uruguay, 2019).

12 "En síntesis, Punta del Este, es sinónimo de un sinfín de alternativas para satisfacer las necesidades de los paladares turísticos más exigentes y heterogéneos." (Ministerio de Turismo del Uruguay, 2019).
} 
Cabe señalar aquí, a propósito del discurso hegemónico, que estamos hablando del relato dominante, lo cual deja de manifiesto que no es el único. En ese sentido, resulta necesario analizar desde dónde se enuncian los relatos, quiénes los producen y quiénes los reproducen, cómo se legitiman y cuáles son los contra-relatos. Por otra parte, esos discursos tienen su correlato visual, sus imágenes. Ellas pueden dar cuenta de la interpretación, de la intención y del sentido de quiénes las producen. Además de registro, la imagen es discurso-discurso visual-y por lo tanto, transmite sentido, comunica posiciones y también genera iconografía. Esto resulta válido, tanto para las imágenes publicitarias, como para las de registro familiar o histórico y también para las artísticas. Todas ellas, asociadas a un territorio, "hablan" sobre ese lugar produciendo sentido, es decir, son producción simbólica, hacen a la cultura de ese lugar, independientemente de su posición crítica o no sobre las relaciones que ahí se suceden.

\section{¿Qué imagen tiene Punta del Este de sí misma?}

En el caso de Punta del Este, como una ciudad balnearia global, cuenta con un discurso visual para su promoción. Todos los agentes del sector turístico local, en conjunto, construyen un relato-el dominante-sobre las preciadas virtudes del lugar, un discurso para vender, esperable en esta dinámica. Algunos lugares comunes, inevitables, por ejemplo, frases como "el balneario más exclusivo" o "con más glamour", aparecen en ese relato, cuya visualidad se traduce en típicas imágenes de sol y playa, de lujosas arquitecturas, de actividades de entretenimiento, etcétera. Estas típicas imágenes de revistas de avión, no opacan la generosa geografía de lugares como Punta del Este cuyo cuidado y preservación constituye un enorme desafío para encontrar el equilibrio entre el desarrollo-o explotación-económico y el cuidado del ambiente. La actual promoción de lugares y servicios, dentro de Punta del Este, más asociados a la naturaleza y la expansión de los emprendimientos hacia la costa atlántica, cuyo avance permitió la concreción del puente sobre la Laguna Garzón, evidencian la necesidad de ese cuidado del ambiente que se encuentra en potencial riesgo.

\section{Relatos posibles a través de las artes visuales}

¿Se pueden identificar momentos, idealizaciones o tensiones propias de las ciudades, a través de las obras artísticas que se producen por y para ellas? Poemas, canciones, novelas, fotografías, dibujos o pinturas, inspiradas en determinado pueblo o ciudad, constituyen representaciones que dependiendo de su lugar de enunciación, nos dicen más o menos cosas sobre ese lugar.

Su análisis, además de considerar su valor estético, en tanto procesos de producción simbólica debidamente legitimados por los agentes del campo artístico correspondiente, pero también su condición de discurso-o relato-de las imágenes, no sólo nos permite indagar en aspectos de la memoria, sino también en posibles implicaciones de la política, en el sentido de la toma de decisiones que 
afectan a toda la comunidad, además de dar cuenta de la relación de ella con su entorno ambiental.

Esta reflexión, sobre la relación de los seres humanos con el ambiente en determinado territorio y sus consecuencias en ese paisaje, se enfocará en las artes visuales, como representaciones y también como dispositivos de memoria. A través de una fotografía, de un dibujo o de un mural, se puede percibir un relato, un discurso, digno de interpretación. La cual, posiblemente, está atravesada por la posición del sujeto en el ambiente donde el dispositivo se activa, es decir, donde ese relato, ese discurso, adquiere sentido. Para que ello suceda, pensando en su aceptación o en su rechazo, tanto el creador, como el espectador deben pertenecer a una misma comunidad interpretativa. Según Fish (1987) la interpretación nunca es un acto individual sino colectivo, determinado siempre por la comunidad: "tiene su fuente en un conjunto de creencias, éstas no son específicas de cada individuo o idiosincrásicas sino comunitarias y convencionales" (p. 236).

En el campo de las artes visuales, para el análisis de algunos ejemplos, se proponen tres categorías posibles de análisis ${ }^{13}$ 1) artes visuales consagradas; 2 ) obras de arte en emprendimientos hoteleros e inmobiliarios; y 3) obras en clave crítica.

La primera se refiere a obras producidas desde la élites y que reflejan elementos canónicos, es decir, son consagradas. A decir de Bloom (1995) sobre el canon occidental, serían aquellas obras que responden a los "principios de selectividad, que son elitistas sólo en la medida en que se fundan en criterios puramente artísticos" (p. 32).

La segunda serían obras financiadas por las élites, más allá de su valor canónico y operan en relación a los intereses del capital, jerarquizando, en tanto obras de arte, los emprendimientos inmobiliarios y hoteleros.

A la tercera la constituyen enunciaciones críticas, más o menos legitimadas por el canon y el mercado pero que cuestionan a las élites. Lo contemporáneo en el campo de las artes visuales, ha saldado de alguna manera esa marginalidad que las expresiones de carácter crítico-no oficial-han tenido a lo largo de buena parte de la historia. Muchas de estas expresiones, si bien juegan con las reglas establecidas por el campo del arte, encuentran intersticios, poros, fisuras, desde dónde enunciar sus críticas.

En clave de artes visuales consagradas, resulta inevitable hacer referencia a aquellas obras de los planistas que inmortalizan paisajes de Punta del Este. El "Muelle las mesitas", recientemente declarado como Bien de Interés Patrimonial ${ }^{14}$, el muelle de La Pastora, y las playas, sobre todo la Mansa, pintados hasta entrada la

\footnotetext{
${ }^{13}$ Cabe señalar que estas categorías no están propuestas como compartimentos estancos sino que adquieren sentido a los efectos de ordenar el análisis pudiendo tener límites difusos e incluso admitir otras categorizaciones posibles.

14 “Según se indica en la Resolución № 00674/2018 esta edificación se encuentra en buen estado general, y su simpleza se integra armónicamente con el paisaje, con una vista panorámica a la Bahía y a la Isla Gorriti" (Intendencia de Maldonado, 2018].
} 
década del 50 por Petrona Viera, dan cuenta no sólo de un interés temático constituyente del Planismo —el paisaje-sino también del atractivo natural que estas costas representaron para artistas foráneos y como discurso visual. No sólo de la memoria histórica, sino también plausible de una lectura ambiental en el sentido de que el registro de un paisaje casi virgen da cuenta de las transformaciones producidas posteriormente por el avance humano sobre el ambiente. En ellas, lo central no es el registro de los cambios arquitectónicos en el paisaje local, sino la contemplación-o sublimación-del paisaje natural. Hay apenas registro de la presencia del hombre en estas obras, lo central es el paisaje. Su cromatismo, con la intención planista de representar fielmente la luz, da cuenta de un paisaje donde el gris y los reflejos no siempre fueron propiedad de la arquitectura (edificios vidriados) sino más bien de la comunión fundante entre el cielo y el mar. Más allá de su valor comercial o patrimonial, estas obras consagradas, por quienes las ejecutaron y por el contexto en el que lo hicieron, resultan referenciales.

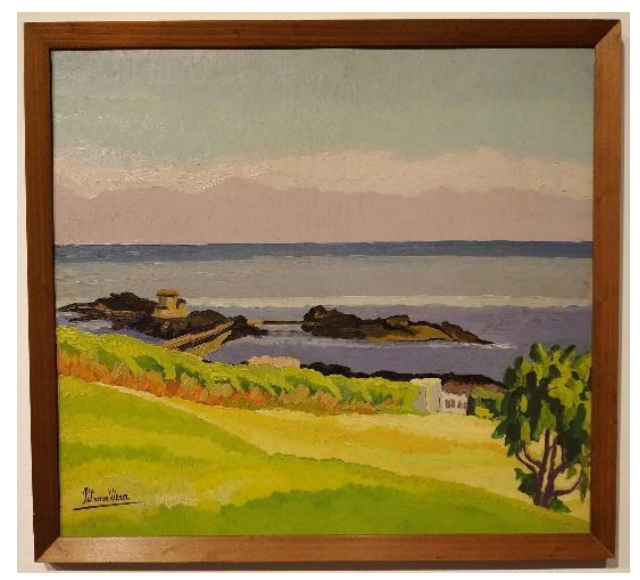

Figura 1. "Playa Mansa”, fotografía de una obra de Petrona Viera tomada en la exposición "El hacer insondable" en el MNAV, 13/3/2020 (Federico Sequeira).

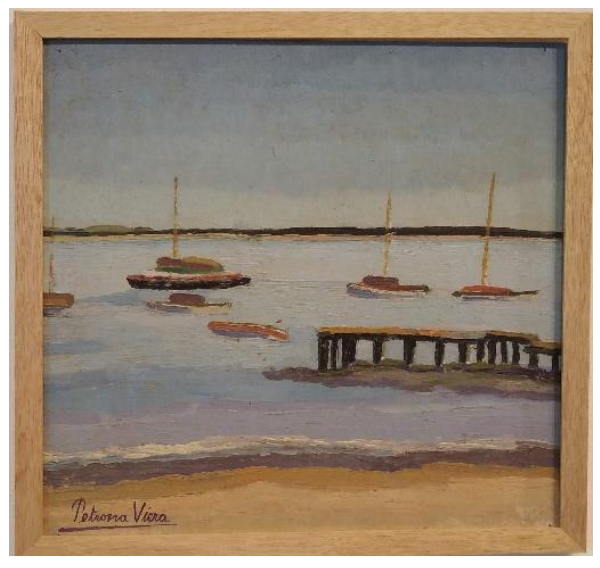

Figura.2. "Playa Mansa", fotografía de una obra de Petrona Viera tomada en la exposición "El hacer insondable" en el MNAV, 13/3/2020 (Federico Sequeira). 
La presencia de obras de arte en emprendimientos hoteleros e inmobiliarios podría considerarse como una suerte de legitimación de esos espacios, en relación a su nivel de exclusividad de acuerdo a las obras de arte que albergan y también en relación a su entorno. Muchos de estos edificios, que suponen una alteración del paisaje y que muchas veces afectan lo patrimonial y lo ambiental, se desarrollan en una lógica donde se pondera la especulación en cuanto a su potencial para generar puestos de trabajo y su eventual captación de turistas de élite que, procurando una nivelación entre su capital económico y cultural, podrían adquirir esas propiedades.

De alguna manera, la alianza de estos proyectos (inmobiliarios y hoteleros) con las artes visuales responden a una estrategia de poner en valor las propiedades horizontales, que supusieron la masificación y cierta amenaza para la exclusividad del balneario, y legitimar esta dinámica especulativa.

Los desaparecidos murales de Norberto Berdía de 1948 en el Hotel San Rafael —hoy demolido-los murales de Dumas Oroño de 1965 en el edificio "Il Campidoglio" de Pintos Risso o las esculturas de Pablo Atchugarry en el edificio "Artower" diseñado por Carlos Ott, son ejemplos posibles de obras financiadas por los inversores en clave de búsqueda de distinción (Bourdieu, 2012) para sus emprendimientos.

\section{Los murales de Norberto Berdía}

La realización de los murales de Norberto Berdía (1948) en el Hotel San Rafael e inaugurados junto al edificio, se debieron, tal como lo señala Hojman (2019), al estrecho vínculo entre el artista y el arquitecto Octavio De los Campos, miembro del estudio ${ }^{15}$ que en 1939 proyectó el hotel:

En el Hotel Casino San Rafael el artista Norberto Berdía pintó un enorme fresco en el gran salón y dos de menor tamaño en el hall de recepción, todos inaugurados con el edificio, en 1948. Este artista fue también el autor de dos obras en los talleres del diario El País: un mural al fresco situado en la sala de redacción y un bajorrelieve ubicado en el sector de acceso, ambos inaugurados en 1953, al mismo tiempo que el edificio. (Hojman, 2019, p. 244)

De los Campos y Berdía se conocían por su participación en la Comisión Nacional de Bellas Artes y su relación se afianzó con el correr de los años. En el fresco principal del conjunto de tres, de gran tamaño, titulado "América" plasmó la

\footnotetext{
${ }^{15}$ Octavio de los Campos (1903-1994), Milton Puente (1905-1980) e Hipólito Tournier (1905-1968) conformaron un estudio de arquitectos que entre sus obras más destacadas se encuentran: El edificio Centenario (1929), el actual Instituto de Profesores Artigas (1937), el Banco La Caja Obrera (1939), el demolido Hotel Casino San Rafael (1939), el ex Banco Mercantil y actual Instituto Nacional de la Juventud (1943), el edificio-taller del de Punta del Este diario "El País" (1952), The British Schools (1955), la Alianza Cultural Uruguay-Estados Unidos (1966). (s/d 2019).
} 
temática latinoamericana, la cual incorporó después de usufructuar una beca en México que le permitió acercarse al muralismo. Hay quienes lo consideran "uno de los exponentes de la corriente del realismo social uruguayo" (Hojman, 2019); otros podrían considerar algo paradójica la temática latinoamericana, asociada a la desigualdad, plasmada en un hotel de lujo. El mismo que siendo sede de eventos centrales de la política internacional, recibió como huésped a Ernesto "Che" Guevara. ${ }^{16}$ No obstante esto, la obra de Norberto Berdía constituye una referencia para las artes visuales nacionales. En ocasión de su fallecimiento, Eduardo Vernazza — también pintor, además de crítico de arte-escribió en el diario "El Día":

Sus decoraciones murales importantes son las del Hotel San Rafael, diario "El País" y el boceto arquitectónico para mural del edificio de la Facultad. (...). Le sorprende la muerte cuando su obra había cimentado ya una gran síntesis de color y concepto plástico. Pierde pues Uruguay otro de sus artistas importantes y de producción sostenida en sus relevantes virtudes. (Vernazza, 1983)

La pérdida de estos murales, no sólo no hace honor a la figura de su autor, sino que empobrece en términos patrimoniales al país y en particular a sus artes visuales.

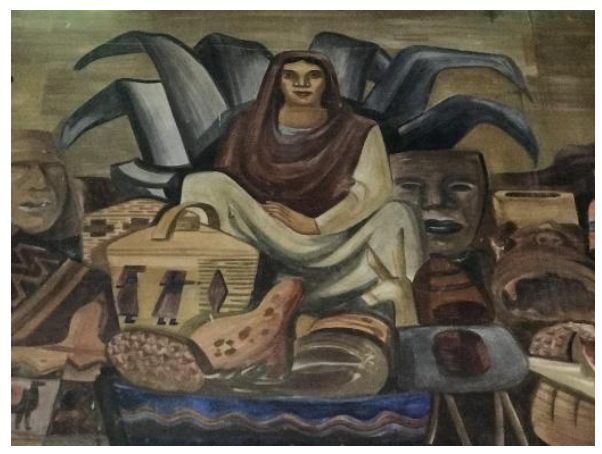

Figura 3. "América", fotografía de un detalle del desaparecido mural realizado por Norberto Berdía (1948) en ex Hotel San Rafael, 2018 (Federico Sequeira).

Resulta interesante señalar que, paradójicamente, el nuevo emprendimiento que se realizará donde se ubicaba el Hotel San Rafael, cuya demolición implicó pérdida de patrimonio para las artes visuales; se promociona utilizando la reproducción de una obra, con la imagen del demolido edificio, realizada en la década del 50 por el acuarelista francés Pierre Fossey.

\section{Los murales de Dumas Oroño}

\footnotetext{
${ }^{16}$ En 1962 el Hotel San Rafael fue sede de la Octava Reunión de Consulta de Ministros de Relaciones Exteriores de la OEA, instancia en la cual se expulsó a Cuba del organismo por su adhesión al marxismo leninismo y en 1967, lo fue de la Reunión de Presidentes de América, ocasión en la que Ernesto "Che" Guevara se alojó en el hotel.
} 
Arquitectos como Walter Pintos Risso o Luis García Pardo se caracterizaron por integrar arte y arquitectura, en la producción de ambos, fundamentalmente durante las décadas del 50 y del 60, pueden verse ejemplos. Si bien la mayoría de ellos se encuentran en Montevideo, algunos ejemplos pueden encontrarse en Punta del Este. En ese sentido, los murales realizados en 1965 por Dumas Oroño en el edificio "Il Campidoglio" de Walter Pintos Risso dan cuenta de ese proceso de integración entre artes visuales y arquitectura, pero también de búsqueda de distinción, dado que había que jerarquizar la construcción en propiedad horizontal, dotarla de exclusividad, relevancia y distinguirla del resto. Para las artes visuales posibilitó además la realización de obras de mayor escala y abiertas al espacio público. A propósito de ello y en relación al Taller Torres García y García Pardo, Medero (2012) señala:

El taller Torres García, de influencia notable en el medio, fue un abanderado de esta integración. Ya en 1940 el arquitecto Ernesto Leborgne había realizado su propia casa, en el barrio Pocitos, integrando la arquitectura con obras artísticas constructivistas y con la naturaleza. Pero mientras los jardines realizados por Leborgne pretenden hablar en un lenguaje universal a un mundo privado y cerrado, las propuestas de García Pardo en todos sus edificios es integrar el arte al espacio público. (p. 18)

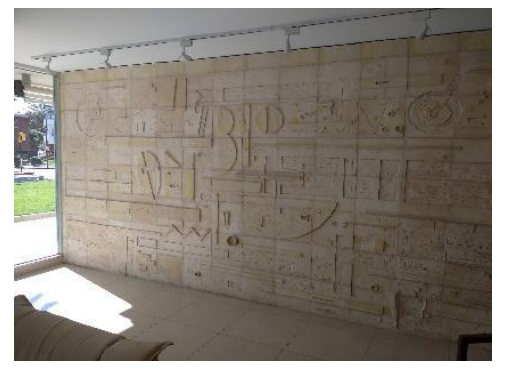

Figura 4. "Mural de Dumas Oroño", fotografía de un detalle del mural (1965) realizado en el edificio "Il Campidoglio", 11/8/2020 (Federico Sequeira).

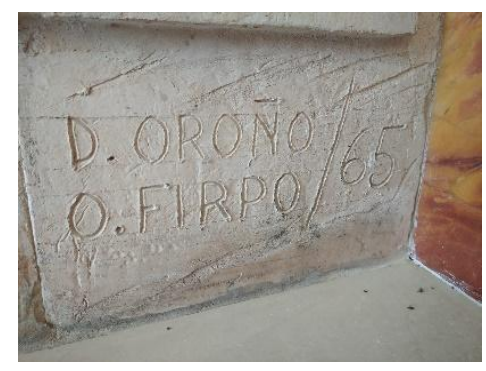

Figura 5. "Mural de Dumas Oroño", fotografía de un detalle del mural (1965) realizado en el edificio "Il Campidoglio", 11/8/2020 (Federico Sequeira). 


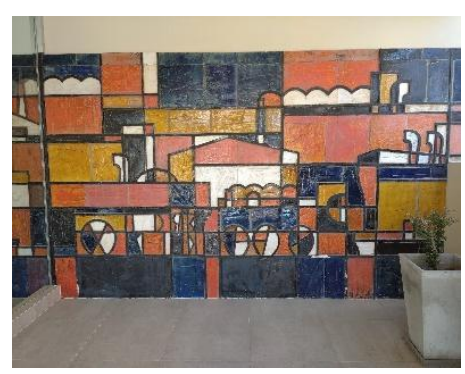

Figura 6. "Mural de Dumas Oroño", fotografía de un detalle del mural (1965) realizado en el edificio "Il Campidoglio", 11/8/2020, Federico Sequeira.

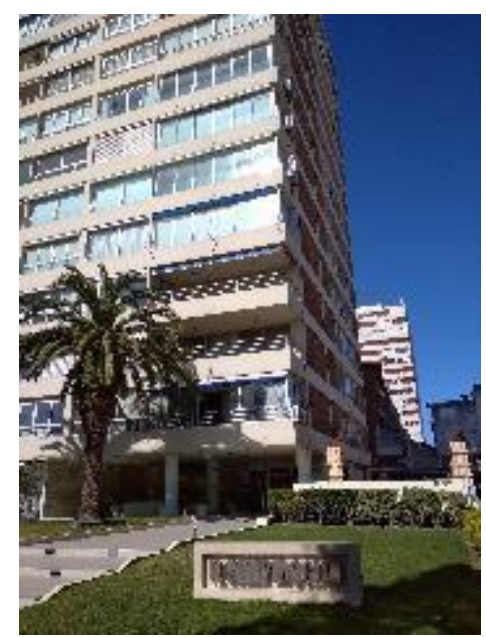

Figura 7. "Il Campidoglio", fotografía de un detalle de la fachada del edificio, 11/8/2020 (Federico Sequeira).

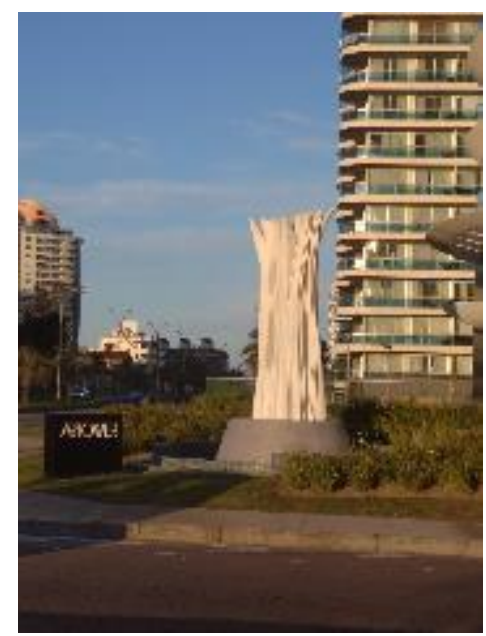

Figura 8. "Escultura de Pablo Atchugarry", fotografía de la obra emplazada a la entrada del edificio "Art Tower", 14/8/2020 (Federico Sequeira): 


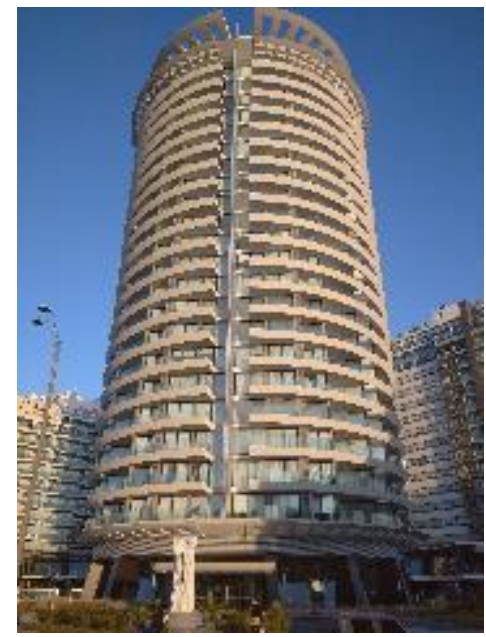

Figura 9. "Art Tower", fotografía de un detalle de la fachada del edificio, 14/8/2020 (Federico Sequeira).

\section{"Artower"}

En 2019 finalizó la construcción de "Artower". Esta "obra de inspiración", según su sitio web oficial ${ }^{17}$, "ha logrado reunir la sensibilidad, el talento y la experiencia de Carlos Ott, Vito Atijas y Pablo Atchugarry". Este emprendimiento del estudio Atijas, logró reunir a dos uruguayos muy reconocidos internacionalmente, el arquitecto Ott y el escultor Atchugarry. Esta integración entre arte y arquitectura, más allá de la discusión sobre el alcance, público o privado, del arte y de las posibilidades para la concreción de obras mayores por parte de los artistas, explícitamente expresa que su objetivo es la distinción, pretende ir más allá de lo que el dinero puede comprar: "Artower presenta un diseño moderno, distinguido, elegante, ambicioso y de características inéditas".

Cualquiera de las obras antes mencionadas-los murales de Berdía y Oroño o las esculturas de Atchugarry-son obras consagradas en el campo de las artes visuales, tanto por su calidad como por su innegable valor estético. Tienen aquí una condición particular: no se trata de obras emplazadas en el espacio público como el recientemente recuperado parque de esculturas "Paseo de las Américas" a la entrada de Punta del Este, sino que se trata de obras emplazadas en emprendimientos privados-hoteles y edificios-cuya presencia de alguna manera jerarquiza esos espacios. Esta jerarquización tiene su traducción en términos económicos, ya que no sale lo mismo un apartamento en una torre con una escultura (de alto valor en el mercado del arte) en el hall de entrada, que uno en cuya entrada haya solo plantas. En ese sentido, sin cuestionar la legitimidad y

\footnotetext{
${ }^{17}$ Según la descripción de los propios creadores: DESCUBRÍ UNA OBRA DE LA INSPIRACIÓN. Ubicado entre las playas Mansa y Brava, a pasos del Hotel Conrad y con las mejores vistas panorámicas de Punta del Este, Artower presenta un diseño moderno, distinguido, elegante, ambicioso y de características inéditas. Una iniciativa exclusiva que ha logrado reunir la sensibilidad, el talento y la experiencia de Carlos Ott, Vito Atijas y Pablo Atchugarry para convertirse en el lanzamiento más importante del año (s/d. 2017).
} 
calidad estética de las obras, podría señalarse que operan en el sentido de la lógica dominante.

Cabe señalar tres aspectos para reflexionar sobre esta alianza: en primer lugar, son obras cuyas temáticas trascienden lo local, los artistas como enunciadores no están ni idealizando el paisaje, como las obras de Petrona Viera que vimos anteriormente, ni tampoco están cuestionando la lógica dominante, como ejemplos que veremos más adelante; son obras de carácter universal que podrían estar emplazadas en cualquier ciudad.

En segundo lugar, representan una integración entre las artes visuales y la arquitectura, dado a que no son obras emplazadas posteriormente a la construcción de los edificios sino que son concebidas como parte del proyecto, para los emprendimientos supone un camino hacia la distinción y para los artistas la posibilidad de realizar obras más ambiciosas desde el punto de vista de su ejecución.

En tercer lugar, si bien no están emplazadas en espacios públicos, al formar parte de espacios comunes de hoteles o edificios suponen un mayor alcance en el sentido de su pasaje de la órbita privada a la pública y además, por estar enmarcadas en emprendimientos comerciales; podría, en ese sentido, suponer beneficios para los artistas, lo cual refuerza esta alianza.

En un sentido contrario a las anteriores, podemos señalar obras en clave crítica, es decir, aquellas que tienen sentido por las lógicas del propio lugar y transmiten una interpretación crítica sobre el mismo. No idealizan el paisaje ni tampoco son de carácter universal; por el contrario, son obras críticas con la lógica dominante y generalmente son enunciadas, en tanto producción de discurso, por artistas locales. Ejemplo de ello podrían ser los proyectos "Moebius" (2018) de Ignacio Rodríguez Srabonián, o el colectivo "Maldonado es..." (2011). ${ }^{18}$

\section{“Moebius"19}

En la descripción inicial, como contracara de la imagen paradisíaca de Punta del Este, se mencionaron algunos aspectos como: las tensiones para la convivencia, como consecuencia de la disputa por determinados territorios, lo cual genera expulsiones de las poblaciones locales y conflictos con los migrantes que arriban al territorio procurando una mejor calidad de vida; las dificultades para el acceso a la vivienda, producidas por la especulación inmobiliaria; la ciudad como espacio sin memoria, sin identidad, como efecto, entre otras cosas, del avasallamiento

\footnotetext{
${ }^{18}$ Proyecto "Maldonado es...". Colectivo integrado por los artistas: Andrés Alvira, Washington Febles Ceriani, Evans Fodrini, Adriana Infantozzi, Gloria Navarro, Mercedes Salazar, Federico Sequeira (Responsable) y Dina Vicente. [Sequeira, F. (2011). Proyecto "Maldonado es..." [Las OBRAS / "Las distintas formas de ver $y$ sentir lo propio"] Recuperado de http://provectomaldonadoes.blogspot.com/2011/08/las-obras-las-distintas-formas-de-ver-y.html] ${ }^{19}$ Para acceder a imágenes del proyecto “Moebius" ingrese a https://www.bienvenidos.biz/
} 
patrimonial producido por las disputas por los territorios, lo cual impacta también en el paisaje; y el debilitamiento del Estado como garante de los derechos ciudadanos.

Todos estos elementos, aparecen en el proyecto "Moebius" del artista visual Ignacio Rodríguez Srabonián que es además, un residente local. Por lo tanto, su mirada crítica es desde adentro, desde la propia lógica y generadora de un contra-relato que irónicamente utiliza, a través del simulacro, los medios habituales de la lógica dominante y de construcción de su relato. Enunciando las consecuencias de la especulación inmobiliaria-lógica dominante-y las disputas por el acceso a la vivienda y a la tierra que ello supone. A propósito del proyecto, Ignacio Alcuri escribió en La Diaria:

(...) Moebius va un paso más allá: además de la instalación de los falsos ranchos en el espacio exclusivo de las mansiones, irrumpe mediante cartelería en la vía pública y se presenta como un emprendimiento de venta de propiedades de lujo en Internet. Para eso, Rodríguez fotografía las casillas en su emplazamiento original (enseguida de montarlas, porque no suelen durar mucho, y esa fragilidad es parte de su potencia discursiva) y luego instala carteles publicitarios que ofrecen las "propiedades" en venta, exactamente como si se tratara de emprendimientos comerciales reales. También forman parte del engaño un showroom en el Espacio de Arte Contemporáneo (EAC) en Montevideo y un sitio web que promociona las precarias estructuras como tentadores negocios inmobiliarios. El simulacro incluye el testimonio de "los vecinos de la 'Manzana $\mathrm{M}$ ', flagrantes realojados del asentamiento El Placer", que fueron desalojados de sus viviendas en una zona lindante con el arroyo Maldonado que ahora será transformada en un espacio de entretenimiento con boliches nocturnos y locales gastronómicos. (Alcuri, 2018)

Resulta interesante el juego, aparentemente contradictorio, que se establece entre lo local y lo global, dado que además de Punta del Este el proyecto incluyó-al menos en la instalación de los ranchos-otras ciudades. Sumado esto a que el proyecto está concebido en clave contemporánea, en términos de artes visuales, esa dimensión global parecería incrementarse. Su condición de local y lo explícito de los elementos que se ponen en juego, operan en términos simbólicos y también de memoria. Si bien estos pueden proponerse en otras latitudes, en cada una adquiere un sentido singular, además la mirada local suele suceder en una sola localidad, no es esta plausible de simulacro. A decir de Andrea Giunta (2014), el arte contemporáneo aporta desde diferentes "dispositivos del recuerdo" a la memoria social y política de las ciudades, intensificando las formas de experimentarlas y estableciendo otras cartografías posibles para su recorrido. Finalmente, el propio proyecto ha propuesto espacios para el debate y la reflexión, que trascendiendo lo estético han resultado instancias de enunciación de los problemas de un modelo turístico que requiere revisión. 
“Maldonado es..."

Si bien este proyecto, que partía desde miradas singulares de cada artista sobre la identidad local, uno de los temas en tensión permanente, abarcaba más allá de Punta del Este como ciudad, surgieron algunas obras que pueden leerse en clave crítica, tales son los casos de las obras "Vene" y "Pertenencias".

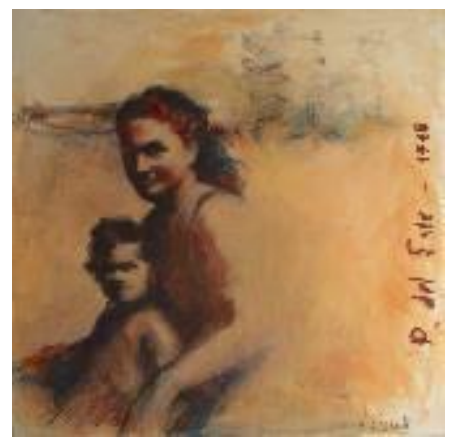

Figura 10. "Vene", fotografía de la obra realizada por Dina Vicente (1945-2014) para el Proyecto "Maldonado es..." (2011).

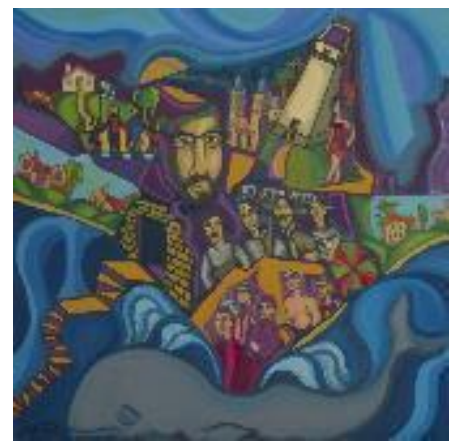

Figura 11. "Pertenencias", fotografía de la obra realizada por Federico Sequeira (1982-) para el Proyecto “Maldonado es...” (2011).

En la primera, "Vene", la autora aparece autorretratada, de niña, junto a su madre en paisaje de playa, en clave de recuerdo. Como una postal, está fechada en un lateral: "P. del Este -1948". Estos elementos, particularmente la fecha, nos refieren a una ciudad muy diferente de la actual, algo insinúa la artista en la difusa línea del horizonte. Parecería predominar cierta añoranza por la ausencia de un ser querido, la madre y también por una ciudad que no es la misma que era. En ese sentido, esta imagen podría ser un ejemplo de los llamados "dispositivos del recuerdo" (Giunta, 2014) propuestos desde el arte contemporáneo, dado que no solo opera en la memoria individual como recuerdo, sino que también lo hace en la memoria social y política de la ciudad.

En el caso de "Pertenencias", también se visualizan elementos de la memoria individual, autobiográficos. Desde ahí se intenta colocarlos en un mapa de la ciudad, se establece una cartografía que es personal pero también colectiva en su sentido social y político. Se parte de cierta ironía-reflejada en el uso de los colores y el estilo casi caricaturesco-para cartografiar, de algún modo, la relación entre los locales y los visitantes y también la apropiación de la costa. 
En ambos casos, proyectos "Moebius" o "Maldonado es...", estamos frente a relatos visuales que son enunciados por locales y adquieren sentido en ese lugar de pertenencia, expresando en estos casos, visiones críticas sobre su lugar. A propósito del relato Ricoeur (2006) decía: "es una mediación entre el hombre y el mundo, entre el hombre y el hombre, entre el hombre y sí mismo" (p. 16). Yo agregaría que el arte también lo es.

\section{A modo de conclusión}

En primer lugar, las artes visuales constituyen "dispositivos del recuerdo" (Giunta, 2014) a través de los cuales se puede interpretar un sentido posible sobre determinado lugar. Estos sentidos que transmiten las obras adquieren mayor o menor inteligibilidad de acuerdo a su contexto. En relación al lugar, las obras pueden ser concebidas como idealización, justificación o crítica. Sin embargo, más allá de la intención del artista o de la mirada individual de cada espectador, el sentido último de la obra responde a un proceso comunitario, es decir, a un conjunto de creencias y códigos compartidos por la comunidad interpretativa (Fish, 1987) a la que pertenecen.

Por otro lado, ese lugar de enunciación desde el cual el artista concibe su obra refleja su posición, no sólo artística, sino también social y política. Es decir, en relación a lo que la obra transmite, está la intención del artista. En los ejemplos de obras que analizamos, hay dos grandes grupos, los que no representan un cuestionamiento para el relato dominante y los que lo cuestionan. Entre estos últimos, se identifican obras de artistas locales, que construyen un relato visual crítico-más allá de los aspectos formales de sus obras-producido desde la vivencia y que, a decir de Ricoeur (2006) resulta en un conjunto de mediaciones: "La mediación entre el hombre y el mundo, es lo que se llama referencialidad, la mediación entre el hombre y el hombre, es la comunicabilidad; la mediación entre el hombre y sí mismo, es la comprensión de sí" (p. 16).

Finalmente, en un territorio turístico, inmerso en la lógica capitalista, las tensiones son múltiples-entre locales y migrantes, entre desarrollo y ambiente, entre paisaje y memoria-por lo cual, los agentes del sector han apelado a la construcción de un relato dominante, capaz de invisibilizar el conflicto y la desigualdad. Las artes visuales, más allá de su valor canónico, de mercado o crítico, transmiten sentido, y más allá de la orientación del mismo, operan en la memoria social y política del territorio (o comunidad). El lugar de enunciación desde donde los artistas conciben sus obras determinará su posición en cuanto a la lógica dominante: pueden ser críticos o no, lo que no pueden ser es neutros. Más allá de si su intención es tal o cual, sus obras operan en la comunidad y esta les asigna un lugar en Punta del Este: puede ser como en el caso de una escultura de Atchugarry a la entrada de la ciudad, o como en el caso de Berdía, bajo los escombros de un hotel demolido en nombre del progreso. 


\section{Referencias}

Bloom, H. (1995). El canon occidental. La escuela y los libros de todas las épocas. Barcelona, España: Editorial Anagrama.

Bourdieu, P. (2012). La distinción. Criterio y bases sociales del gusto. Madrid, España:Taurus.

Fish, S. (1987). ¿Hay algún texto en esta clase? Cambridge (MA), Estados Unidos: Harvard University Press.

Giunta, A. (2014). ¿Cuándo empieza el arte contemporáneo? Buenos Aires, Argentina: Fundación arteBA.

Medero, S. (2012). Luis García Pardo. Montevideo, Uruguay: Instituto de Historia de la Arquitectura, FADU - UdelaR.

Yúdice, G. (2002). El recurso de la cultura. Barcelona, España: Ed. Gedisa.

Hojman, M. (2019). Interacciones. El arte en la obra del estudio. En: L. Alemán, (coord.), De los Campos, Puente, Tournier. Obras y proyectos (pp. 243-287). Montevideo, Uruguay: Instituto de Historia de la Arquitectura, FADU UdelaR.

Ricoeur, P. (2006). La vida: un relato en busca de narrador. Agora, 25(2), 9-22.

Sassen, S. (1995). La ciudad global: una introducción al concepto y su historia. Brown Journal of World Affairs, 11(2), 27-43.

Vernazza, E. (14/3/1983). Falleció el Pintor Norberto Berdía. El Día.

Ajmat, S. (2018, enero 11). Punta del Este, ¿la Miami del Sur? La Nación. Recuperado de: https://www.lanacion.com.ar/sociedad/punta-del-este-la-miami-del-sur-ni $\underline{\mathrm{d} 2098066}$

Alcuri, I. (2018, julio13). Un techo para mi país. La Diaria. Recuperado de: https://ladiaria.com.uy/cultura/articulo/2018/7/un-techo-para-mi-pais/

Martínez, M. (2019, setiembre 3). Uruguay destruye su patrimonio arquitectónico. El País.

Recuperado de: 
https://elpais.com/cultura/2019/08/31/actualidad/1567210170717908. $\underline{\mathrm{html}}$

Ministerio de Turismo del Uruguay. (2019). Punta del Este. Recuperado de: https://turismo.gub.uy/index.php/lugares-para-ir/region-este/ciudades/p unta-del-este

Intendencia de Maldonado. (2018). IDM declaró Bien de Interés Patrimonial al "Muelle Las Mesitas". Recuperado de: http://www.maldonado.gub.uy/?n=33345\&mi=PuntadelEste

Rodríguez Srabonián, I. (2018). Moebius. Punta del Este: Proyecto Moebius. Recuperado de: https://www.bienvenidos.biz/

Nómada.(2019). Nómada. Montevideo: FADU - UdelaR. Recuperado de: http://www.nomada.uy/guide/view/authors/2557

Artower Uruguay. Punta del Este: Atijas Casal Arquitectos. (2017). Recuperado de: http://artower.com.uy/

Sequeira, F. (2011). Proyecto "Maldonado es..." [Las OBRAS / "Las distintas formas de ver y sentir lo propio"] Recuperado de: http://proyectomaldonadoes.blogspot.com/2011/08/las-obras-las-distinta s-formas-de-ver-y.html 